\title{
Unmet Need for Family Planning in Sri Lanka: Low Enough or Still an Issue?
}

By Deborah S. DeGraff and K.A.P. Siddhisena

Deborah S. DeGraff is professor, Department of Economics,

Bowdoin College,

Brunswick, ME, USA.

K.A.P. Siddhisena is professor emeritus, Department of Demography, University of Colombo, Sri Lanka.
CONTEXT: Family planning efforts achieved considerable success in Sri Lanka during the late 20th century; however, overall levels and trends may mask relatively high levels of unmet need under certain conditions.

METHODS: Data from the 2007 Demographic and Health Survey of Sri Lanka (DHS-SL) were used to estimate unmet need for limiting and spacing births among ever-married women aged 15-49, overall and by key characteristics. Twelve definitions of unmet need of varying stringency were used to assess the sensitivity of results to a variety of measurement issues. Comparable estimates from the 1987 DHS-SL were used to provide context on changes in unmet need over time.

RESULTS: Total unmet need in 2007 ranged from 1.6\% under the narrowest definition to $19.3 \%$ under the broadest. Levels of unmet need for spacing births in 2007 were lower than $3 \%$ for all measures and for most subsamples. In contrast, levels of unmet need for limiting were generally higher and more varied, both in relation to the definition of unmet need used and across subsamples. Unmet need for limiting was particularly high in certain groups if women's use of traditional contraceptive methods and practice of prolonged abstinence were considered not to meet their contraceptive need.

CONCLUSIONS: Continued progress regarding contraceptive prevalence and method mix could contribute to further reducing unmet need for family planning in Sri Lanka and to meeting women's reproductive and health goals. Renewed policy emphasis on the family planning needs and concerns of selected groups would promote such goals.

International Perspectives on Sexual and Reproductive Health, 2015, 41(4):200-209, doi: 10.1363/4120015
More than 200 million women in developing countries want to avoid pregnancy, yet are not using a modern contraceptive method. ${ }^{1}$ Each year, such unmet need for contraception results in an estimated 54 million unintended pregnancies, as well as more than one million infant deaths and 79,000 maternal deaths. ${ }^{1,2}$ At the July 2012 London Summit on Family Planning, world leaders and family planning experts emphasized the importance of addressing unintended pregnancy and unmet need for contraception in developing countries. The summit resulted in FP2020, a global partnership with the goal of providing family planning services-including access to effective yet reversible contraceptive methods-to an additional 120 million women by the year 2020, thereby cutting unmet need in half. ${ }^{3}$

Three important strands of thought underlie the goals resulting from the London Summit. First, since the 1990s, both the international community and developing country governments have shifted their thinking in regard to the objectives of family planning services away from an emphasis on fertility reduction and toward one on women's reproductive rights and maternal and child health. ${ }^{4-6}$ Second, strong evidence has accumulated of the potential negative consequences of unintended pregnancies for the health and well-being of women and their families. ${ }^{1,2,7,8}$ Third is the argument that increased use of modern contraceptives, especially reversible methods, and decreased reliance on traditional methods will lower the incidence of unintended pregnancy. ${ }^{1,3,9-11}$ Implicit in the latter point is the idea that such changes will result in improvements in meeting women's family planning goals and the promotion of reproductive health. These concepts were embedded in the 2007 decision to include universal access to reproductive health among the Millennium Development Goals, with unmet need as one of the indicators to be monitored.,

This study contributes to the goals of FP2020 by examining unmet need in Sri Lanka. Since the 1980s, Sri Lanka has experienced a growing emphasis on reversible modern contraceptive methods and a continued rise in contraceptive prevalence. ${ }^{12-15}$ As a result, its total fertility rate (TFR) declined substantially until the mid-1990s, but has since remained slightly above replacement fertility. Unmet need was estimated to be as high as 31\% among married women of reproductive age in $1987 .{ }^{16}$ For this study, we used data from 2007 (the most recent year for which appropriate data are available) to determine whether levels of unmet need have declined in Sri Lanka. Furthermore, we investigated whether unmet need is experienced similarly across subsets of the population and whether the conclusions are sensitive to variations in measurement. Our re- 
sults may be useful in further supporting women and their families in meeting their reproductive goals and attaining high levels of maternal and child health.

\section{SRI LANKAN CONTEXT}

The period since the 1980s has been a time of substantial change for Sri Lanka. ${ }^{17-20}$ Its economy has not only expanded and become less based in agriculture, it is also more global and free-market. Employment opportunities within Sri Lanka and internationally have increased, especially for young women, as have education levels; however, secondary and tertiary schooling have outpaced employment, resulting in periods of high unemployment and underemployment among relatively well educated young adults. $^{21,22}$

At the same time, the population of Sri Lanka is aging, even more so than in most Asian countries, ${ }^{12,13,23,24}$ which has strained the resources of many young families responsible for caring for older relatives. In addition, the latter 20th and early 21st centuries were characterized by uncertainty associated with the civil unrest between the central government and the Liberation Tigers of Tamil Eelam, which has only recently ceased. Finally, the period has been characterized by technological advances in effective reversible methods of contraception worldwide, and by greater availability and knowledge of such methods in Sri Lanka.

Within this context, family planning behavior in Sri Lanka has continued to change. Among married women of reproductive age, contraceptive prevalence rose rapidly, from $34 \%$ in 1975 to $62 \%$ in $1987,{ }^{25,26}$ mostly because of increased use of female sterilization and traditional methods (primarily rhythm and withdrawal), ${ }^{27,28}$ and then increased much less rapidly over the subsequent two decades, to about $70 \%$ by $2007 .^{13,26}$ Reliance on traditional contraceptive methods declined between 1987 and 2007, whereas modern method use increased (from $41 \%$ to $53 \%$ ). This greater reliance on modern contraceptives was facilitated by the increased availability of reversible methods, as reflected by a shift in the ratio of sterilization to reversible modern methods from 3 to 1 in 1987 to 1 to 2 in 2007. ${ }^{26}$ Thus, even though the more recent increase in contraceptive prevalence was not as dramatic as the earlier one, the decisions and experiences of Sri Lankan women with respect to family planning changed considerably by 2007.*

The increase in contraceptive prevalence and method choice have facilitated couples' achievement of their fertility goals and contributed to the health of women and their children. According to survey data, the TFR reached replacement level in 1994, ${ }^{\dagger}$ having declined from 5.5 in the 1950s to 3.6 by 1974 and 2.8 by $1987^{12-15,26,29-32}$ While the early decline was primarily attributable to increasing age at marriage, declining age-specific fertility within marriage drove the trend from the 1970s onward. ${ }^{12,13,17,27,28,33}$ This trend was in large measure facilitated by policy. Since its establishment, the Sri Lankan government has placed substantial emphasis on health and other aspects of social development. It became concerned with high fertility and rapid population growth as early as the 1950s, and by 1965 had articulated a national family planning policy under the auspices of the Ministry of Health. ${ }^{1,12-14,34}$ A strong policy emphasis on family planning and fertility reduction continued through the end of the century and supported the increased availability of an array of family planning services and modern contraceptive methods. However, international support for family planning began to decline around this time, and from the mid-1990s to 2008, funding for family planning programs worldwide decreased by an estimated 30\%. ${ }^{1,4,6,35,36}$ Similarly, in Sri Lanka, the policy emphasis on family planning began to diminish, and recent administrations have adopted a somewhat more pronatalist stance in rhetoric and policy. ${ }^{14,17,36,37}$ The latest official statistics for Sri Lanka show an increase in fertility in recent years to clearly above replacement level (TFR, 2.4 in 2011). ${ }^{15}$

Against this policy backdrop, we closely examine levels of unmet need for family planning in Sri Lanka. Does the relatively high contraceptive prevalence rate coupled with the relatively low fertility rate imply that unmet need is no longer an issue? Or, conversely, are there areas where a renewed policy emphasis on family planning could make an important contribution to women's achievement of their reproductive goals?

\section{DATA AND METHODS}

The primary goal of this analysis was to gain a better understanding of the nature of the remaining unmet need for family planning in Sri Lanka at the time of the 2007 Demographic and Health Survey of Sri Lanka (DHS-SL). We do so in two ways: by considering differences in levels of unmet need by alternative measures, and by evaluating levels of unmet need by several key characteristics of the population, such as age, education, ethnicity, number of children ever born and sector of residence. ${ }^{\ddagger}$ Such information, while not itself intended to be used to identify the contraceptive needs of individual women, can be useful in identifying differences across subsets of the population, which can inform the targeting or tailoring of family planning services.

The data used in this analysis come from the 2007 DHS-SL, the most recent available ${ }^{26}$ in addition, we used data from the 1987 DHS-SL to provide context on changes

*Statistics on contraceptive prevalence and method mix for the 2007 analysis sample are available from the authors.

tEstimates based on vital registration data suggest that, while consistent with the general trends in fertility derived from survey data, the decline in fertility might not have reached replacement level.(Source:Wijesekere $\mathrm{G}$ and Arunachalam D, Explaining the fertility puzzle in Sri Lanka, Journal of Biosocial Science, 2015, 47(6):845-852.)

$\ddagger$ As is customary in Sri Lanka, sector of residence distinguishes between three sectors: urban, rural and estate. The estate sector comprises tea plantations populated largely by descendants of individuals originating in the Tamil region of India who were brought in as laborers during the British colonial period. Such individuals and their families are often referred to as Indian Tamils; other Sri Lankans of Tamil origin-historically concentrated in the north and east-are referred to as Sri Lankan Tamils. 
TABLE 1. Alternative definitions of unmet need for contraception, and percentage of ever-married women aged 15-49 with unmet need according to each definition, by type of need, Sri Lanka, 2007

\begin{tabular}{|c|c|c|c|c|c|c|c|}
\hline \multirow[t]{2}{*}{ Definition } & \multirow[t]{2}{*}{ Current/recent pregnancy } & \multirow{2}{*}{$\begin{array}{l}\text { Wants to limit } \\
\text { or space births }\end{array}$} & \multirow{2}{*}{$\begin{array}{l}\text { Practicing } \\
\text { prolonged } \\
\text { abstinence }\end{array}$} & \multirow{2}{*}{$\begin{array}{l}\text { Practicing } \\
\text { contraception }\end{array}$} & \multicolumn{3}{|c|}{ \% unmet need } \\
\hline & & & & & Total & Limiting & Spacing \\
\hline 1 & No & Yes & No & No & 1.6 & 1.4 & 0.2 \\
\hline 2 & No & Yes or uncertain & No & No & 1.8 & 1.5 & 0.3 \\
\hline 3 & No & Yes or uncertain & Yes or no & No & 4.5 & 3.6 & 0.9 \\
\hline 4 & No & Yes & No & No or traditional & 12.7 & 11.7 & 1.1 \\
\hline 5 & No & Yes or uncertain & No & No or traditional & 13.6 & 12.3 & 1.3 \\
\hline 6 & No & Yes or uncertain & Yes or no & No or traditional & 17.8 & 15.8 & 2.0 \\
\hline 7 & No or unwanted/mistimed & Yes & No & No & 2.2 & 1.9 & 0.3 \\
\hline 8 & No or unwanted/mistimed & Yes or uncertain & No & No & 2.4 & 2.0 & 0.4 \\
\hline 9 & No or unwanted/mistimed & Yes or uncertain & Yes or no & No & 5.6 & 4.5 & 1.1 \\
\hline 10 & No or unwanted/mistimed & Yes & No & No or traditional & 13.6 & 12.5 & 1.2 \\
\hline 11 & No or unwanted/mistimed & Yes or uncertain & No & No or traditional & 14.5 & 13.1 & 1.4 \\
\hline 12 & No or unwanted/mistimed & Yes or uncertain & Yes or no & No or traditional & 19.3 & 17.1 & 2.2 \\
\hline
\end{tabular}

over time. ${ }^{38}$ Each survey's sample includes ever-married women aged 15-49 and is nationally representative, except for oversampling to ensure adequate representation of selected groups and for exclusion of provinces heavily affected by civil strife. The 1987 survey excluded the Northern and Eastern Provinces for the latter reason; the 2007 survey included the Eastern Province, which constitutes 5.6\% of the 2007 sample. Our analysis of the 2007 data derives measures both excluding and including the Eastern Province, to be comparable over time and also as complete as possible. The analysis sample was based on the subset of women currently married or in union-5,449 women in 1987, and 13,711 in 2007 (excluding the Eastern Province). All calculated measures of unmet need were adjusted for sample weighting to render them representative of the population of the included provinces.

To examine unmet need, we used twelve alternative measures developed for a previous analysis of 1987 DHSSL data. ${ }^{16}$ We specified multiple measurement options based on areas of sensitivity identified in the unmet need

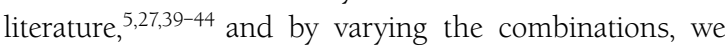
created a range of definitions of women with unmet need that vary in stringency (Table 1). The first and most narrow definition is limited to fecund women not currently or recently pregnant who definitely want to limit or space births and are not practicing prolonged abstinence or any form of contraception. Definition 2 broadens definition 1 by including women who are uncertain about wanting to limit or space their childbearing, as well as those who definitely want no more. Definition 3 broadens definition 2 by also including women who are practicing prolonged abstinence. Next, we derived definitions 4,5 and 6 by expanding definitions 1, 2 and 3, respectively, to include users of traditional contraceptive methods among those with unmet need. Finally, we derived a second set of six definitions (7-12), by broadening definitions $1-6$ to also include women with a current or recent pregnancy that was unwanted or mistimed. ${ }^{9,42-44}$ We divided each measure of total unmet need into unmet need for limiting and unmet

*Detailed subsample counts used in the calculation of unmet need-for the least and most inclusive measures-that illustrate the steps of the methodology are available from the authors. need for spacing, on the basis of whether women desired a birth interval of at least two years to identify spacing.

This methodology is consistent with the recommendations of the Technical Expert Working Group on Unmet Need for Family Planning. ${ }^{5,40}$ First, regarding two key areas of concern identified in the report, we neither rely on a contraceptive calendar nor incorporate information on the strength of respondents' feelings about a future pregnancy. Second, as recommended, we use a reference period of two years to define "recent" when considering current and recent pregnancies. It is important to acknowledge, however, that any measure of this sort is likely to underestimate the extent of unwantedness (and, therefore, of unmet need) due to ex-post rationalization or reluctance to speak of living children as unwanted. $8,45,46$ In contrast, it has been suggested that measures that accord with the recommendations might overestimate unmet need by not considering women's intentions regarding contraceptive use. ${ }^{45}$

As context for our analysis of unmet need in 2007, we include information about the extent to which unmet need has declined since 1987 using measures of unmet need derived previously from the 1987 DHS-SL; detailed results for 1987 are presented in our earlier work. ${ }^{16}$ Changes in unmet need since 1987 were determined by taking the difference between the 1987 and 2007 measures. Key to such an analysis is that the measures be comparable across time. ${ }^{10,40}$ The degree of correspondence across the two surveys in the questions relevant to defining unmet need is very high. ${ }^{38,47}$ In addition, we use the same computer algorithm for calculating unmet need for each survey.

\section{RESULTS}

\section{Full Sample}

We present estimated levels of unmet need-expressed as a percentage of all women in the 2007 sample-for each of the 12 measures (Table 1).* For brevity, only the results from data excluding the Eastern Province are shown; any insights gained from including the Eastern Province are noted in the text.

Overall, the level of unmet need is quite sensitive to which definition is used. For example, total unmet need in 2007 ranged from 1.6\% using definition 1 to $19.3 \%$ us- 
ing definition 12. Unmet need for limiting had a similarly wide range across measures (1.4-17.1\%); however, unmet need for spacing was uniformly low across measures (0.2$2.2 \%$ ). In general, the level of total unmet need as well as the levels of unmet need for limiting and spacing were most sensitive to whether the definition used included women who reported practicing prolonged abstinence or using a traditional contraceptive method; the levels were much less sensitive to the categorization of women who were uncertain about their fertility preferences. For example, the levels of unmet need for limiting using definitions 1 and 2 were virtually the same ( $1.4 \%$ and $1.5 \%$, respectively); however, the level was higher using definition 3 (3.6\%), and substantially higher using definition 6 (15.8\%). This pattern holds for total unmet need and unmeet need for spacing, as well as for the analogous second set of definitions (7-12) that include women with a current or recent unwanted or mistimed pregnancy. Finally, the levels of unmet need based on definitions that include women with a current or recent unwanted or mistimed pregnancy were higher than those based on the analogous definitions that do not. For example, the levels of unmet need for limiting using definitions 1 and 7 were $1.4 \%$ and 1.9\%, respectively. The impact of this definitional variant on unmet need for limiting and spacing generally was less than that of the treatment of prolonged abstinence or traditional method use, but more than that of uncertain fertility preferences.

In analyses including data from the Eastern Province, the same basic patterns are seen in the levels of unmet need, with only slight differences in values. For example, when we used the most inclusive definition, the levels of unmet need for limiting and spacing for the expanded sample were $16.6 \%$ and $2.6 \%$, respectively (not shown); in comparison, those levels for the sample excluding the Eastern Province were $17.1 \%$ and 2.2\%. Unmet need for spacing for each of the 12 definitions was somewhat higher in the expanded sample, which suggests greater unmet need for spacing in that region. Total unmet need and unmet need for limiting were higher using the expanded sample only when traditional family planning methods were considered to meet contraceptive need. This is because of a greater reliance on modern methods in the Eastern Province, especially female sterilization and injection, and a lower prevalence of traditional method use.

Between 1987 and 2007, Sri Lanka (excluding the Eastern Province) experienced a decrease in unmet need for spacing of $78-93 \%$, depending on the measure used (not shown). In comparison, unmet need for limiting generally decreased less over the period and the size of decrease varied more by the measure used.* Combined, these trends led to the very low levels of unmet need for spacing in 2007 and the substantially higher levels of unmet need for limiting, especially with the more inclusive measures. As mentioned above, the largest value of unmet need for lim-

*Detailed estimates of the decline in unmet need between 1987 and 2007 are available from the authors. iting in 2007 was 17.1\%-nearly 90\% of the level of total unmet need (19.3\%). In other words, based on this variation, the vast majority of Sri Lanka's remaining total unmet need can be attributed to unmet need for limiting. In contrast, based on the same measure, only about $63 \%$ of total unmet need in 1987 was attributable to unmet need for limiting. A consistently high proportion of total unmet need in 2007 (80-92\%) can be attributed to unmet need for limiting, regardless of which measure is used.

\section{Results by Key Characteristics}

To better understand unmet need for family planning in Sri Lanka in 2007, we replicated the analysis above by key characteristics of the population-sector of residence, ethnicity, age, number of children born, employment status, and woman's and her husband's education-using selected

\begin{tabular}{|c|c|c|c|c|c|c|}
\hline \multirow[t]{2}{*}{ Characteristic } & \multicolumn{3}{|c|}{ Limiting } & \multicolumn{3}{|c|}{ Spacing } \\
\hline & Def. 1 & Def.3 & Def.6 & Def.1 & Def.3 & Def.6 \\
\hline \multicolumn{7}{|l|}{ Sector } \\
\hline Urban & 1.8 & 4.7 & 17.5 & 0.4 & 1.6 & 2.7 \\
\hline Rural & 1.2 & 3.3 & 16.1 & 0.2 & 0.8 & 1.9 \\
\hline Estate & 3.4 & 5.5 & 7.1 & 0.6 & 2.0 & 2.6 \\
\hline \multicolumn{7}{|l|}{ Ethnicity } \\
\hline Sinhalese & 1.2 & 3.1 & 16.4 & 0.1 & 0.7 & 1.8 \\
\hline Sri Lankan Tamil & 2.2 & 6.3 & 11.9 & 0.7 & 2.6 & 3.5 \\
\hline Indian Tamil & 3.2 & 6.5 & 8.0 & 0.9 & 2.5 & 3.3 \\
\hline Moor/Malay & 3.4 & 6.3 & 14.9 & 0.7 & 1.8 & 3.2 \\
\hline Other & 6.6 & 8.0 & 21.9 & 0.0 & 2.3 & 2.3 \\
\hline \multicolumn{7}{|l|}{ Age } \\
\hline $15-19$ & 0.0 & 0.4 & 0.7 & 0.0 & 2.8 & 5.1 \\
\hline $20-24$ & 1.0 & 1.3 & 2.2 & 0.0 & 2.4 & 4.7 \\
\hline $25-29$ & 1.0 & 1.8 & 4.8 & 0.0 & 1.8 & 4.2 \\
\hline $30-34$ & 1.8 & 3.2 & 11.3 & 0.2 & 1.1 & 2.2 \\
\hline $35-39$ & 2.1 & 5.3 & 21.8 & 0.1 & 0.5 & 1.4 \\
\hline $40-44$ & 1.8 & 4.8 & 27.3 & 0.1 & 0.1 & 0.2 \\
\hline $45-49$ & 1.8 & 4.3 & 23.6 & 0.0 & 0.0 & 0.0 \\
\hline \multicolumn{7}{|c|}{ No.of children born } \\
\hline 0 & 0.3 & 0.5 & 1.3 & 0.5 & 0.6 & 1.4 \\
\hline 1 & 0.7 & 2.0 & 8.2 & 0.5 & 2.3 & 4.8 \\
\hline 2 & 1.8 & 4.9 & 24.0 & 0.3 & 0.7 & 1.7 \\
\hline 3 & 1.5 & 4.1 & 19.0 & 0.0 & 0.1 & 0.4 \\
\hline 4 & 2.1 & 4.5 & 15.8 & 0.0 & 0.1 & 0.2 \\
\hline 5 & 1.5 & 4.0 & 13.5 & 0.0 & 0.0 & 0.0 \\
\hline 6 & 6.1 & 9.3 & 15.1 & 0.0 & 0.0 & 0.0 \\
\hline$\geq 7$ & 10.8 & 12.6 & 24.7 & 0.0 & 0.0 & 0.0 \\
\hline \multicolumn{7}{|l|}{ Employed } \\
\hline No & 1.5 & 3.8 & 14.2 & 0.3 & 1.3 & 2.4 \\
\hline Yes & 1.2 & 3.2 & 18.1 & 0.1 & 0.4 & 1.4 \\
\hline \multicolumn{7}{|c|}{ Woman's education } \\
\hline No formal & 2.0 & 2.1 & 7.8 & 0.5 & 0.8 & 1.3 \\
\hline Some primary & 2.0 & 3.1 & 13.3 & 0.1 & 0.1 & 0.6 \\
\hline Some secondary & 1.2 & 2.1 & 14.5 & 0.3 & 0.4 & 1.9 \\
\hline$\geq$ secondary & 1.3 & 2.5 & 19.2 & 0.2 & 0.5 & 2.7 \\
\hline \multicolumn{7}{|c|}{ Husband's education } \\
\hline No formal & 1.9 & 3.8 & 11.1 & 0.3 & 0.5 & 1.0 \\
\hline Some primary & 1.6 & 3.1 & 12.6 & 0.2 & 0.6 & 1.0 \\
\hline Some secondary & 1.3 & 3.8 & 14.8 & 0.3 & 0.9 & 2.0 \\
\hline$\geq$ secondary & 1.3 & 3.5 & 19.3 & 0.2 & 1.1 & 2.5 \\
\hline
\end{tabular}


measures of unmet need (1, 3, 6, 7, 9 and 12). This selection provides lower- and upper-bound estimates of unmet need, and also highlights the points of greater measurement sensitivity discussed in the previous section. Definitions 1, 3 and 6 (and, analogously, 7, 9 and 12) emphasize sensitivity to the treatment of prolonged abstinence and use of traditional methods, whereas comparisons between the two sets emphasize sensitivity to the treatment of unwanted or mistimed births.

The most striking result from these analyses is the consistently low unmet need for spacing throughout the population in 2007. The level of unmet need for spacing was less than 3\% for almost all groups and measures (Table 2, page 203 and Table 3). This reflects the widespread and substantial declines in unmet need for spacing since 1987 throughout much of the population (not

\begin{tabular}{|c|c|c|c|c|c|c|}
\hline \multirow[t]{2}{*}{ Characteristic } & \multicolumn{3}{|c|}{ Limiting } & \multicolumn{3}{|c|}{ Spacing } \\
\hline & Def.7 & Def.9 & Def.12 & Def.7 & Def.9 & Def. 12 \\
\hline \multicolumn{7}{|l|}{ Sector } \\
\hline Urban & 2.2 & 5.8 & 19.0 & 0.4 & 1.6 & 2.9 \\
\hline Rural & 1.7 & 4.2 & 17.4 & 0.3 & 0.9 & 2.0 \\
\hline Estate & 3.6 & 6.4 & 8.1 & 0.8 & 2.3 & 3.0 \\
\hline \multicolumn{7}{|l|}{ Ethnicity } \\
\hline Sinhalese & 1.6 & 4.0 & 17.7 & 0.2 & 0.9 & 2.0 \\
\hline Sri Lankan Tamil & 2.5 & 7.3 & 13.1 & 0.7 & 2.6 & 3.5 \\
\hline Indian Tamil & 3.6 & 7.3 & 8.8 & 1.0 & 2.9 & 3.6 \\
\hline Moor/Malay & 4.3 & 7.8 & 17.1 & 0.7 & 2.0 & 3.4 \\
\hline Other & 6.6 & 9.4 & 23.2 & 0.0 & 2.3 & 2.3 \\
\hline \multicolumn{7}{|l|}{ Age } \\
\hline $15-19$ & 0.0 & 1.4 & 1.7 & 2.0 & 5.0 & 7.3 \\
\hline $20-24$ & 0.3 & 1.7 & 2.6 & 1.2 & 3.4 & 5.7 \\
\hline $25-29$ & 0.8 & 2.4 & 5.4 & 0.5 & 2.0 & 4.4 \\
\hline $30-34$ & 1.7 & 3.8 & 11.9 & 0.3 & 1.1 & 2.2 \\
\hline $35-39$ & 2.8 & 6.6 & 23.2 & 0.1 & 0.5 & 1.4 \\
\hline $40-44$ & 2.3 & 5.5 & 28.8 & 0.0 & 0.1 & 0.2 \\
\hline $45-49$ & 2.9 & 6.1 & 26.6 & 0.0 & 0.0 & 0.0 \\
\hline \multicolumn{7}{|c|}{ No. of children born } \\
\hline 0 & 0.2 & 0.8 & 1.7 & 0.8 & 1.6 & 2.4 \\
\hline 1 & 0.8 & 2.4 & 8.7 & 0.6 & 2.6 & 5.0 \\
\hline 2 & 2.5 & 6.0 & 25.5 & 0.3 & 0.7 & 1.7 \\
\hline 3 & 2.3 & 5.2 & 20.5 & 0.0 & 0.2 & 0.5 \\
\hline 4 & 2.4 & 5.6 & 18.3 & 0.0 & 0.1 & 0.2 \\
\hline 5 & 4.0 & 6.9 & 17.1 & 0.0 & 0.0 & 0.0 \\
\hline 6 & 6.9 & 12.0 & 17.8 & 0.0 & 0.0 & 0.0 \\
\hline$\geq 7$ & 13.7 & 15.5 & 27.6 & 0.0 & 0.0 & 0.0 \\
\hline \multicolumn{7}{|l|}{ Employed } \\
\hline No & 2.1 & 5.0 & 15.7 & 0.4 & 1.5 & 2.7 \\
\hline Yes & 1.7 & 3.8 & 19.2 & 0.1 & 0.5 & 1.4 \\
\hline \multicolumn{7}{|c|}{ Woman's education } \\
\hline No formal & 2.3 & 5.3 & 8.6 & 0.5 & 1.0 & 1.3 \\
\hline Some primary & 2.9 & 5.1 & 15.0 & 0.1 & 0.2 & 0.6 \\
\hline Some secondary & 1.7 & 4.5 & 15.7 & 0.4 & 1.2 & 2.2 \\
\hline$\geq$ secondary & 1.7 & 4.3 & 20.6 & 0.3 & 1.2 & 2.8 \\
\hline \multicolumn{7}{|c|}{ Husband's education } \\
\hline No formal & 2.3 & 5.2 & 12.9 & 0.6 & 0.9 & 1.4 \\
\hline Some primary & 2.1 & 4.3 & 14.1 & 0.2 & 0.6 & 1.1 \\
\hline Some secondary & 2.0 & 4.7 & 16.1 & 0.4 & 1.1 & 2.3 \\
\hline zsecondary & 1.7 & 4.2 & 20.5 & 0.3 & 1.3 & 2.6 \\
\hline
\end{tabular}

shown). For example, in analyses by age-group, the decrease in unmet need for spacing from 1987 to 2007 was $70 \%$ or greater for almost all groups and measures; the percentage decreases were especially large for women aged 20-39, the stage of women's life during which birth spacing is most relevant. Levels of unmet need for spacing in 2007 were somewhat higher-up to 7\%-among younger women (ages 15-29), women who had given birth to only one child and members of certain ethnic groups, when the most inclusive measures (definitions 6 and 12) were used.

Overall, the patterns across characteristic groups with respect to alternative definitions of unmet need for spacing were the same as the pattern for the sample as a whole. The level of unmet need increased with more inclusive definitions of unmet need and again highlights the sensitivity of results to the treatment of prolonged abstinence and traditional family planning methods; however, because the differences were small in absolute terms, they are of little practical importance. Also, similar to the results for the full sample, incorporating unwanted or mistimed births had little effect on the level of unmet need for spacing for most groups. The groups that experienced the largest relative increases along this dimension were the youngest women (15-24), and those with no children, living in the estate sector and whose husband had no formal schooling. These subsets of the population appear somewhat more prone to experiencing (or at least reporting) mistimed recent or current pregnancies.

In contrast to unmet need for spacing births, there was considerable variation in unmet need for limiting by key characteristics. Some of this variation, such as by age, is to be expected given that Sri Lankan women overwhelmingly prefer not to limit births at young ages. However, it is notable that this indicator of unmet need is fairly high among the three oldest age-groups using the more inclusive measures (definition 6, 22-27\%; definition 12 , 23-29\%). Although this pattern across age-groups holds when traditional methods are considered to meet need for limiting (definitions 1, 3, 7 and 9), the values were lower and within a narrower range (all $<7 \%$ ). This indicates a fairly heavy reliance on traditional methods for birth limiting among older women.

An interesting pattern emerged when we examined unmet need for limiting by women's number of births, illustrated using definitions 9 and 12, which differ only with respect to the classification of traditional methods (Figure 1, page 205). The pattern was the same in both cases, just with substantially lower levels of unmet need when traditional methods were considered to meet need: Unmet need for limiting was very low for parities 0 and 1 , increased substantially at parity 2 , and then followed a U-shaped pattern to parity $\geq 7$. This bimodal distribution suggests that parity 2 has become normative and that it is not only women at high parity who seek to limit fertility.

Unmet need for limiting varied little by women's employment status, regardless of the measure used; however, we found more sizeable differences by level of education- 
both of the woman and of her husband. When measures that do not consider traditional methods to meet need were used (definitions 6 and 12), unmet need for limiting was greatest among the group with the highest education level and declined with each lower level. When traditional methods were counted as meeting need (definitions 1, 3, 7 and 9), this pattern disappeared, which indicates highly educated individuals' greater reliance on traditional methods to limit births.

We also found striking differences in unmet need for limiting by location of residence and ethnicity. Regarding residence and, again, using definitions 6 and 12, unmet need for limiting was much lower in the estate sector than in rural or urban areas, between which differences were small. As with education above, this pattern disappeared when traditional methods were considered to meet contraceptive need, because of the comparatively low reliance on such methods for limiting births in the estate sector where female sterilization is widely used. A similar pattern was found by ethnicity, specifically comparing the Indian Tamil ethnic group to the majority Sinhalese. Indian Tamils are concentrated in the estate sector and make up the majority of the population in those areas, whereas the Sinhalese are distributed throughout rural and urban areas. Among the Sinhalese, unmet need for limiting is sharply lower when traditional methods are viewed as meeting need than when they are viewed as not meeting need (e.g., 3\% using definition 3 vs. 16\% using definition 6), consistent with a heavy reliance on such methods for limiting in this group. Overall, using the most inclusive definition (12), the values across ethnic groups in unmet need for limiting range from $9 \%$ to $23 \%$. These differences are greatly reduced when traditional methods are counted as satisfying need for limiting (ranges, 3-8\% using definition 3 and 4-9\% using definition 9).

Implicit in the discussion above is the additional result that estimates of unmet need for limiting across key characteristics were much more sensitive to differences in measurement than were estimates of unmet need for spacing. In the case of unmet need for spacing, the use of alternative measures resulted in very small absolute differences in the estimates of unmet need by key characteristics. In contrast, for some characteristics, the extent to which estimates of unmet need for limiting differ across subsets of the population and even in which direction they differ was highly sensitive to the measure used. This was especially obvious in relation to the treatment of traditional family planning methods vis-à-vis patterns across age-groups, education levels, sector of residence and ethnicity. Finally, as in the full sample, the estimates of unmet need for limiting by key characteristics were less sensitive to the treatment of prolonged abstinence, and even less so to the treatment of unwanted pregnancies. These two types of sensitivities to alternative definitions were generally highly uniform across categories of any particular characteristic and, thus, do not alter conclusions regarding the patterns of unmet need for limiting births by key characteristics.

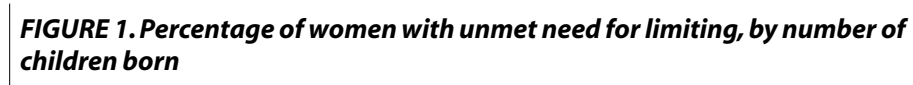
children born

$\%$

100
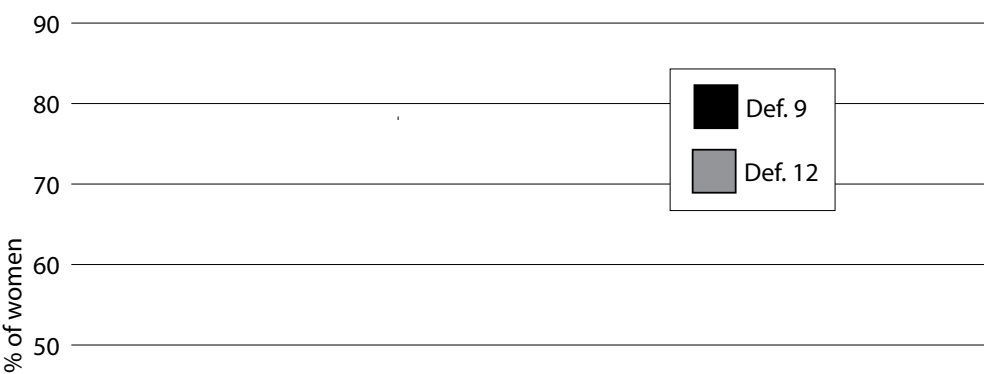

40

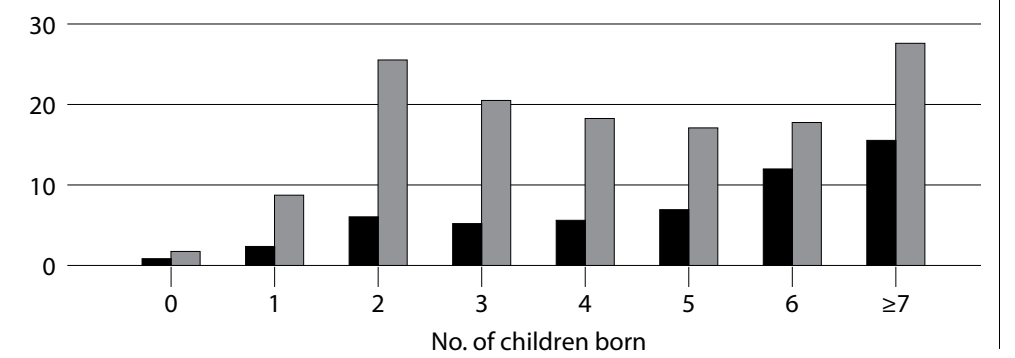

\section{DISCUSSION}

This analysis provides several insights that can inform efforts to further enhance the ability of women in Sri Lanka to achieve their reproductive goals. First, the results indicate substantial and widespread progress in reducing unmet need for spacing births. Remaining pockets of unmet need for spacing exist among women younger than 30, those who have had only one child and, more broadly, those in the Eastern Province. Further strengthening the provision of information about and support for the voluntary use of reversible modern methods among young women of low parity-who, along with women in the estate sector, displayed greater reporting of mistimed births-could be an effective strategy. Also, efforts to emphasize the health benefits of birthspacing for women and children among young mothers might prove useful. With respect to the estate sector, it has been argued that the quality of health services in general is lower than elsewhere, and that family planning services have overemphasized sterilization; ${ }^{48}$ to the extent that these concerns are valid, ensuring access to and support for a wide array of family planning methods in the estate sector, both for spacing and limiting births, would be an important policy focus. Likewise, regarding the Eastern Province (and probably also the Northern Province, which is not represented in the data but likely faces similar conditions), as these regions gradually recover from decades of civil unrest, it is important to ensure that family planning services comparable to those elsewhere are widely available, both for spacing and limiting births and including modern methods other than sterilization and injection.

Second, our results indicate that Sri Lanka also made 
progress between 1987 and 2007 in reducing unmet need for limiting, yet to a lesser degree than that for spacing. Unmet need continues to be greater for limiting than for spacing throughout the population, with particularly high levels among a few groups, if traditional family planning methods and to a lesser extent prolonged abstinence are considered as not meeting contraceptive need. We found that reliance on traditional methods for limiting in Sri Lan$\mathrm{ka}$ is fairly widespread-unusually so for a country with such high overall contraceptive prevalence. ${ }^{49}$ This raises the questions of whether women who use such methods are satisfied and whether such methods are effective in preventing pregnancy. In other words, should traditional methods be considered as meeting family planning needs in Sri Lanka? While it is beyond the scope of our analysis to definitely answer this question, we present a variety of evidence that speaks to the issue below.

The long-standing dominant view in the family planning literature is that traditional methods of contraception are less effective than modern methods in preventing pregnancy-a perspective that underpins FP2020 and was integral to the evolution of the Sri Lankan family planning program in the latter decades of the 20th century. Furthermore, several studies set in Sri Lanka provide evidence that is consistent with this perspective. For example, using data from the 1982 Contraceptive Prevalence Survey (CPS) combined with a 1985 follow-up, De Silva shows that the concordance of stated fertility intentions with subsequent outcomes is higher for users of modern methods than for users of traditional methods. ${ }^{50}$ Similarly, Kane et al. used 1985 CPS data and found that traditional method users were more likely than modern method users to report contraceptive failure as the reason for switching methods, ${ }^{41}$ and Hamill et al. found in a 1986 survey of rural women that when users of traditional methods experience a contraceptive failure, they tend to switch to a modern method. ${ }^{51}$

In contrast, studies set in Sri Lanka and elsewhere question whether temporary modern methods are in fact superior to traditional methods with respect to effectiveness or other criteria. ${ }^{10,52-56}$ General arguments in support of this view include the lack of reliable data on the use and effectiveness of traditional methods, the greater concerns about side effects and health issues associated with modern than with traditional methods and the high effectiveness of traditional methods in particular contexts (e.g., individuals with high method knowledge). In Sri Lanka, there is a long history of experience with traditional family planning methods. ${ }^{27,56}$ This knowledge base is supported by relatively high levels of education overall and among women in particular, a strong policy emphasis on health care and a fairly high degree of gender equity. Such conditions are likely to promote the use of traditional methods and enhance their effectiveness. Moreover, previous studies suggest that women in Sri Lanka are more likely to express concern about side effects or health issues associated with modern methods than with traditional ones. ${ }^{27,41,56}$

We also considered these issues using the 2007 DHS-
SL, to the extent that the data allow. ${ }^{57}$ For women not practicing contraception, we examined questions regarding reasons for nonuse and for not planning to use. In addition, we examined reasons for discontinuing contraceptive use among those who had done so in the past five years. The resulting evidence-when viewed within the context of the role of traditional family planning methods in Sri Lanka-cuts both ways. On the one hand, there continues to be evidence of a higher likelihood of contraceptive failure among users of traditional methods, along with evidence of some normative influences that may discourage adoption of modern methods. In addition, a significant proportion of respondents attribute their nonuse or discontinuation to subfecundity or infecundity, but the methodology for calculating unmet need has already removed those who, according to the unmet need literature, should be in this category. Thus, it is possible that such women are more fecund than they believe.

On the other hand, the evidence makes apparent ongoing concerns about side effects or health issues associated with modern family planning methods. Furthermore, our analysis suggests that traditional methods are more widely used to limit births by more highly educated and older women than by their less educated and younger counterparts. Perhaps, as suggested above, their higher levels of education, greater life experience or norms regarding sexual relations at older ages translate into effective and satisfactory use of such methods. Finally, almost no respondents identified lack of knowledge of or access to family planning methods, or cost of methods, as their main reason for not practicing contraception.

Given these arguments and illustrative evidence, our most inclusive estimate of unmet need for limiting in Sri Lanka may well be an overestimate, erroneously attributing unmet need to users of traditional methods when there is none. However, it would not be appropriate to assume no unmet need among users of traditional methods in Sri Lanka. Further efforts to distinguish between these alternative scenarios would be helpful to ensure that women are well positioned to meet their fertility and reproductive health goals. For example, it would be valuable to have a better understanding of concerns about health issues and side effects associated with modern contraceptive methods-both among users of traditional methods and among nonusers-to assess whether women have accurate information. In addition, it would be especially useful to focus on women in the latter portion of their reproductive life, as well as on those with high parity and those who have had two children, to better understand and address unmet need for limiting. The latter group, in particular, might be reluctant to adopt an irreversible method of family planning. Thus, efforts to strengthen outreach about temporary modern methods for the purpose of limiting would be useful. Among older women, it would be valuable to assess more thoroughly the degree of satisfaction with traditional methods, and to increase knowledge about fecundity and of ways to enhance the effectiveness 
of traditional methods.

With a contraceptive prevalence rate of 70\% in 2007 and fertility only slightly above replacement level, Sri Lan$\mathrm{ka}$ is clearly among the success stories of the latter 20th century in terms of the ability of the population to achieve their reproductive goals and improve maternal and child health, despite a fairly low level of gross national income per capita. ${ }^{58}$ However, a review of contraceptive prevalence rates in developing countries found rates as high as $75-80 \%$ in some countries as of $2004 .{ }^{59}$ In addition, the report of the 2012 census in Sri Lanka reiterates the goal of reaching replacement-level fertility. ${ }^{15}$ The evidence presented here on levels of unmet need for family planning and patterns of unmet need by key characteristics suggests that there is room for continued progress in Sri Lanka regarding contraceptive prevalence and perhaps also method mix that could make an important contribution to women's achievement of their reproductive and health goals.

Finally, this analysis provides ample evidence of sensitivity of results to variations in the definition used to measure unmet need. This is particularly the case with respect to unmet need for limiting and the treatment of traditional family planning methods. To a lesser extent, it is also true in regard to the practice of prolonged abstinence. In contrast, results were not sensitive to the incorporation of uncertain fertility preferences, because such responses are by now rare in Sri Lanka. The treatment of reported unwanted recent births had a modest effect on the level of unmet need for limiting births, but generally did not alter conclusions regarding patterns of unmet need across groups. Future assessments of unmet need for family planning in Sri Lanka-especially unmet need for limiting births-should account for these areas of measurement sensitivity, and should look closely at the circumstances surrounding the use of traditional family planning methods.

\section{REFERENCES}

1. Bongaarts J et al., Family Planning Programs for the 21st Century: Rationale and Design, New York: Population Council, 2012.

2. Singh S, Sedgh G and Hussain R, Unintended pregnancy: worldwide levels, trends, and outcomes, Studies in Family Planning 2010, 41(4):241-250.

3. Brown W et al., Developing the " 120 by 20 " goal for the Global FP2020 Initiative, Studies in Family Planning, 2014, 45(1):73-84.

4. Blanc AK and Tsui AO, The dilemma of past success: insiders views on the future of the international family planning movement, Studies in Family Planning, 2005, 36(4):263-276.

5. Bradley SEK and Casterline JB, Understanding unmet need: history, theory, and measurement, Studies in Family Planning, 2014, 45(2):123-150.

6. Ross J and Smith E, Trends in national family planning programs, 1999, 2004 and 2009, International Perspectives on Sexual and Reproductive Health, 2011, 37(3):125-133.

7. Campbell M, Sahin-Hodoglugil NN and Potts M, Barriers to fertility regulation: a review of the literature, Studies in Family Planning, 2006, $37(2): 87-98$.

8. Gipson JD, Koenig MA and Hindin MJ, The effects of unintended pregnancy on infant, child, and parental health: a review of the literature, Studies in Family Planning, 2008, 39(1):18-38.
9. Casterline JB and El-Zeini LO, Unmet need and fertility decline: a comparative perspective on prospects in Sub-Saharan Africa, Studies in Family Planning, 2014, 45(2):227-245.

10. Cleland J, Harbison S and Shah IH, Unmet need for contraception: issues and challenges, Studies in Family Planning, 2014, 45(2):105-122.

11. Seiber EE, Bertrand JT and Sullivan TM, Changes in contraceptive method mix in developing countries, International Family Planning Perspectives, 2007, 33(3):117-123.

12. Abeykoon ATPL, Fertility transition in Sri Lanka: the determinants and consequences, paper prepared for United Nations Economic and Social Commission for Asia and the Pacific Seminar on Fertility Transition in Asia: Opportunities and Challenges, Bangkok, Thailand, Dec. 18-20, 2006.

13. Abeykoon ATPL, The demographic transition: opportunities and challenges-the case of Sri Lanka, paper presented at the 27th Asian Parliamentarians' Meeting on Population and Development: The World Population at 7 Billion, Mount Lavinia, Sri Lanka, July 18-19, 2011

14. De Silva WI, Perera BN and Anuranga KC, Below to above replacement: dramatic increase in fertility and its determinants in Sri Lanka, Asia-Pacific Population Journal, 2010, 25(2):27-52.

15. Sri Lanka Department of Census and Statistics, Census of Population and Housing 2012 Key Findings, Colombo, Sri Lanka: Department of Census and Statistics, 2014.

16. DeGraff DS and de Silva V, Unmet need for contraception in Sri Lanka, International Family Planning Perspectives, 1991, 17(4):123-130.

17. Caldwell BK and Caldwell JC, Below-replacement fertility: determinants and prospects in South Asia, Journal of Population Research, 2003, 20(1):19-34.

18. Sri Lanka Ministry of Labour Relations and Manpower, Labour and Social Trends in Sri Lanka, Colombo, Sri Lanka: Ministry of Labour Relation and Manpower, 2012.

19. United Nations Development Program (UNDP), Sri Lanka Human Development Report 2012, Bridging Regional Disparities for Human Development, Colombo, Sri Lanka: UNDP, 2012.

20. UNDP, Sri Lanka National Human Development Report 2014 on Youth and Development, Colombo, Sri Lanka: UNDP, 2014

21. Malhotra A and DeGraff DS, Entry versus success in the labor force: young women's employment in Sri Lanka, World Development, 1997, 25(3):379-394

22. Malhotra A and DeGraff DS, Daughters and wives: marital status, poverty and young women's employment in Sri Lanka, in: Garciá B, ed., Women, Poverty and Demographic Change, Oxford, England Oxford University Press, 2000, pp. 145-174.

23. Siddhisena KAP and DeGraff DS, A pace of its own: the demography of ageing in Sri Lanka, Journal of Population Ageing, 2010, 2(3-4):77-99.

24. United Nations Population Fund, Ageing Population in Sri Lanka: Issues and Future Prospects, Colombo, Sri Lanka: United Nations Population Fund, 2004

25. Sri Lanka Department of Census and Statistics, World Fertility Survey Sri Lanka 1975, First Report, Colombo, Sri Lanka: Sri Lanka Department of Census and Statistics, 1978

26. Sri Lanka Department of Census and Statistics, Sri Lanka Demographic and Health Survey 2006/7: Preliminary Report, 2008, http://www.statistics.gov.lk/social/DHS\%20Sri\%20Lanka\%20 Preliminary\%20Report.pdf.

27. Caldwell J et al., The role of traditional fertility regulation in Sri Lanka, Studies in Family Planning, 1987, 18(1):1-21.

28. Gajanayake I and Caldwell J, Fertility and its control: the puzzle of Sri Lanka, International Family Planning Perspectives, 1990, 16(3):97102 \& 111.

29. Alam I and Cleland J, Illustrative analysis: recent fertility trends in Sri Lanka, World Fertility Survey Scientific Reports, London: World Fertility Survey, 1981, No. 25. 
30. De Silva WI, Ahead of target: achievement of replacement level fertility in Sri Lanka before the year 2000, Asia-Pacific Population Journal, 1994, 9(4):3-22

31. Sri Lanka Department of International and Social Affairs, Socioeconomic Development and Fertility Decline in Sri Lanka, New York: United Nations, 1986

32. Siddhisena KAP, Determinants and implications of fertility trend in Sri Lanka: retrospect and prospect, Sri Lanka Journal of Population Studies, 2000, 3:35-58

33. Retherford RD and Rele JR, A decomposition of recent fertility changes in South Asia, Population and Development Review, 1989, 15(4):739-747

34. Jayewardene JR, President Jayewardene on Sri Lanka's population policies and programs, Population and Development Review, 1979, 5(4):742-747.

35. Bongaarts J and Sinding SW, A response to critics of family planning programs, International Perspectives on Sexual and Reproductive Health, 2009, 35(1):39-44.

36. Caldwell JC, Phillips JF and Barkat-e-Khuda, The future of family planning programs, Studies in Family Planning, 2002, 33(1):1-10.

37. Dangalle N, Controlling population growth in Sri Lanka: perceptions, policies and strategies, Sri Lanka Journal of Population Studies, 1998, 1(1):1-24 \& 124

38. Sri Lanka Department of Census and Statistics and Institute for Resource Development/Westinghouse (IRD), Sri Lanka Demographic and Health Survey 1987, Columbia, MD, USA: IRD, 1988

39. Becker S and Sutradhar SC, Fertility intentions: are the undecided more like those who want more or want no more children? Journal of Biosocial Science, 2007, 39(1):137-145.

40. Bradley SEK et al, Revising unmet need for family planning, DHS Analytical Studies, Calverton, MD, USA: ICF International, 2012, No.

41. Kane TT, Gaminiratne KHW and Stephen EH, contraceptive method switching in Sri Lanka: patterns and implications, International Family Planning Perspectives, 1988, 14(2):68-75

42. Nortman DL, Measuring the unmet need for contraception to space and limit births, International Family Planning Perspectives, 1982, 8(4):125-134

43. Westoff CF, The potential demand for family planning: a new measure of unmet need and estimates for five Latin American countries, International Family Planning Perspectives, 1988, 14(2):45-

44. Westoff CF and Pebley AR, Alternative measures of unmet need for family planning in developing countries, International Family Planning Perspectives, 1981, 7(4):126-136.

45. Callahan R and Becker S, Unmet need, intention to use contraceptives and unwanted pregnancy in rural Bangladesh, International Perspectives on Sexual and Reproductive Health, 2014 40(1):4-10.

46. Casterline JB and El-Zeini LO, The estimation of unwanted fertility, Demography, 2007, 44(4):729-745.

47. Sri Lanka Department of Census and Statistics, Sri Lanka Demographic and Health Survey 2006-07, www.statistics.gov.lk/social/ DHS\%20200607\%20FinalReport.pdf, 2009.

48. Balasundaram S, Stealing wombs: sterilization abuses and women's reproductive health in Sri Lanka's tea plantations, Indian Anthropologist, 2011, 41(2):57-78.

49. Bertrand JT et al., Contraceptive method skew and shifts in method mix in low- and middle-income countries, International Perspectives on Sexual and Reproductive Health, 2014, 40(3):144-153.

50. De Silva WI, Consistency between reproductive preferences and behavior: the Sri Lankan experience, Studies in Family Planning, 1991, 22(3):188-197.

51. Hamill DN, Tsui AO and Thapa S, Determinants of contraceptive switching behavior in rural Sri Lanka, Demography, 1990, 27(4):559-
578

52. Basu AM, Ultramodern contraception: social class and family planning in India, Asian Population Studies, 2005, 1(3):303-323.

53. Erfani A, Factors associated with the use of withdrawal in Iran: Do fertility intentions matter? Journal of Comparative Family Studies, 2012, 43(2):301-312.

54. Erfani A and Yuksel-Kaptanoglu I, The use of withdrawal among birth limiters in Iran and Turkey, Studies in Family Planning, 2012, 43(1):21-32.

55. Rogow D and Horowitz S, Withdrawal: a review of the literature and an agenda for research, Studies in Family Planning, 1995 26(3):140-153.

56. Yapa L and Siddhisena P, Locational specificities of fertility transition in Sri Lanka, GeoJournal, 1998, 45(3):177-188.

57. Special tabulations of data from the 2007 Sri Lanka Demographic and Health Survey.

58. UNDP, Human Development Report 2011, New York: Palgrave MacMillan, 2011.

59. Ross J, Abel E and Abel K, Plateaus during the rise of contraceptive prevalence, International Family Planning Perspectives, 2004, 30(1):39-44.

\section{RESUMEN}

Contexto: Los esfuerzos en planificación familiar alcanzaron un éxito considerable en Sri Lanka a fines del siglo XX; sin embargo, los niveles y las tendencias globales pueden ocultar niveles relativamente altos de necesidad insatisfecha bajo ciertas condiciones.

Métodos: Se usaron datos de la Encuesta Demográfica y de Salud 2007 de Sri Lanka (DHS-SL) para estimar la necesidad insatisfecha de limitar y espaciar partos en mujeres de 15 a 49 años que alguna vez estuvieron casadas, en general y por características clave. Se usaron 12 definiciones de necesidad insatisfecha con diferentes grados de rigor para evaluar la sensibilidad de los resultados respecto de una variedad de aspectos de medición. Se usaron estimaciones comparables de la DHS-SL 1987 para aportar información de contexto sobre cambios en la necesidad insatisfecha a lo largo del tiempo.

Resultados: La necesidad insatisfecha total en 2007 varió de 1.6\% con la definición más estrecha a 19.3\% con la más amplia. Los niveles de necesidad insatisfecha de espaciar partos en 2007 fueron menores al 3\% para todas las medidas y para la mayoría de las submuestras. En contraste, los niveles de necesidad insatisfecha de limitar partos fueron en general más altos y más variados, tanto en relación con la definición de necesidad insatisfecha usada como en las submuestras. La necesidad insatisfecha de limitar fue especialmente alta en ciertos grupos cuando el uso de métodos anticonceptivos tradicionales y la práctica de la abstinencia prolongada no satisfacian la necesidad anticonceptiva de las mujeres.

Conclusiones: El avance sostenido en la prevalencia de uso de anticonceptivos y en la mezcla de métodos podría contribuir a reducir aún más la necesidad insatisfecha de planificación familiar en Sri Lanka, y a cumplir con las metas reproductivas $y$ de salud de las mujeres. En materia de políticas públicas, un énfasis renovado en las necesidades y preocupaciones de planificación familiar de grupos selectos promovería tales metas. 


\section{RÉSUMÉ}

Contexte: Les efforts de planification familiale ont remporté un succès considérable au Sri Lanka à la fin du 20e siècle. Les tendances et les niveaux globaux masquent cependant peutêtre un besoin non satisfait relativement élevé dans certaines conditions.

Méthodes: Les données de l'Enquête démographique et de santé 2007 du Sri Lanka (EDS-SL) ont servi à estimer le besoin non satisfait de limitation et d'espacement des naissances parmi les femmes de 15 à 49 ans mariées ou l'ayant jamais été, globalement et par caractéristiques clés. Douze définitions plus ou moins strictes du besoin non satisfait ont permis d'évaluer la sensibilité des résultats à différents problèmes de mesure. Des estimations comparables de l'EDS-SL 1987 contextualisent l'évolution du besoin non satisfait au fil du temps.

Résultats: En 2007, le besoin total non satisfait varie entre 1,6\% sous la définition la plus étroite et 19,3\% sous la plus large. Les niveaux de besoin non satisfait d'espacement des naissances en 2007 sont inférieurs à 3\% pour toutes les mesures et pour la plupart des sous-échantillons. Par contre, ceux de limitation sont généralement plus élevés et plus variables, tant par rapport à la définition utilisée que sur l'ensemble des sous-échantillons. Le besoin non satisfait de limitation apparaît particulièrement élevé dans certains groupes quand le recours des femmes aux méthodes contraceptives traditionnelles et l'abstinence prolongée sont considérés comme ne répondant pas à leur besoin de contraception.

Conclusions: La progression continue de la prévalence contraceptive et de l'éventail de méthodes pourraient contribuer à réduire davantage le besoin non satisfait de planification familiale au Sri Lanka et à atteindre les objectifs de procréation et de santé des femmes. L'accentuation politique renouvelée des besoins et préoccupations de planification familiale de certains groupes favoriserait ces objectifs.

\section{Acknowledgments}

The authors acknowledge the Sri Lanka Department of Census and Statistics for allowing them access to the data. Funding from the Bill \& Melinda Gates Institute for Population and Reproductive Health was used by the authors to attend the 2013 International Conference on Family Planning in Addis Ababa, Ethiopia, at which they presented an early version of this analysis and received helpful feedback.

Author contact: ddegraff@bowdoin.edu 